\title{
The genus Dicopomorpha (Hymenoptera, Mymaridae) in Africa and a key to Alaptus-group genera
}

\author{
John T. Huber \\ Canadian Forest Service clo AAFC, 960 Carling Ave., Ottawa, ON, K1A 0C6, Canada \\ urn:lsid:zoobank.org:author:6BE7E99B-9297-437D-A14E-76FEF6011B10 \\ Corresponding author: John T. Huber (john.huber@agr.gc.ca)
}

Academic editor: Norman Johnson | Received 03 March 2009 | Accepted 25 June 2009 | Published 14 September 2009

urn:lsid:zoobank.org:pub:EDB3610D-09CA-4A42-81AC-D4281CD79A15

Citation: Huber JT (2009) The genus Dicopomorpha (Hymenoptera, Mymaridae) in Africa and a key to Alaptus-group genera. In: Johnson N (Ed) Advances in the systematics of Hymenoptera. Festschrift in honour of Lubomír Masner. ZooKeys 20: 233-244. doi: 10.3897/zookeys.20.116

\begin{abstract}
Dicopomorpha zebra Huber, sp. n. (Hymenoptera, Mymaridae) is described as the first species of Dicopomorpha (Ogloblin) from the Afrotropical region, and diversity in the genus is discussed. Kubja Subba Rao is placed in synonymy under Dicopus Enock, syn. n., and its type species transferred to Dicopus as D. longipes (Subba Rao), comb. n. A key to the Alaptus-group of genera (Alaptus, Dicopomorpha, Dicopus, Kikiki, and Mimalaptus) is presented.
\end{abstract}

\section{Keywords}

Mymaridae, Dicopomorpha, Alaptus, Dicopus, Kikiki, Mimalaptus, Dicopomorpha zebra; taxonomy

\section{Introduction}

Ogloblin (1955) described Dicopomorpha together with three other new genera, Callodicopus, Chromodicopus, and Dicopulus, from Argentina. The latter two names were synonymized under Dicopomorpha by Yoshimoto (1990). Noyes and Valentine (1989) assigned an undescribed species from New Zealand to Dicopomorpha, which represented the first published record for the genus in the Australasian region. Triapitsyn and Berezovskiy (2003) noted that the generic limits of Dicopomorpha needed redefinition

Copyright J.T. Huber. This is an open access article distributed under the terms of the Creative Commons Attribution License, which permits unrestricted use, distribution, and reproduction in any medium, provided the original author and source are credited. 
based on a worldwide study, described a new species from South Korea, and provided a key to the two known eastern Palaearctic species, one of which had been transferred to Dicopomorpha from Alaptus Westwood by Triapitsyn and Huber (2000). Triapitsyn and Berezovskiy (2004) transferred another species to Dicopomorpha from Litus Haliday and suggested it represents a distinct and diverse species-group of Dicopomorpha in the Australasian and eastern Palearctic regions. Dicopomorpha was also reported from the Nearctic region by Huber (1997) and Mockford (1997) so that the genus has been recorded from all continents except Africa.

Huber and Lin (1999) included Dicopomorpha in their newly defined Alaptusgroup of genera along with Alaptus, Dicopus Enock, Kubja Subba Rao, and Mimalaptus Noyes \& Valentine. Lin et al. (2007) also included five genera in an expanded definition of the Alaptus-group that excluded Kubja but included Kikiki Huber \& Beardsley. Here I describe a new species of Dicopomorpha from the Afrotropical region, making the genus almost worldwide in distribution, and present a key to the Alaptus-group of genera.

I dedicate this contribution to that intrepid collector of small parasitic wasps, Lubomír Masner. His over 50 years of passion and single mindedness in collecting far and wide using as many techniques as possible, some very novel, has resulted in a greater understanding of the diversity and abundance of many groups of Hymenoptera. The resulting collections made by him and others are invaluable for appreciating the tremendous diversity of small parasitic wasps, which permits much better understanding and resolution of genera than if only small scattered collections were available for study.

\section{Methods}

Specimens of the new Dicopomorpha sp. were critical point dried and card or point mounted. Two specimens were slide mounted for detailed study. Measurements are given in micrometres. Specimens are deposited in the Natural History Museum, London, UK (BMNH) and the Canadian National Collection of Insects, Ottawa, Canada (CNC). Photographs were taken with a ProgRes C14 $4^{\text {plus }}$ digital camera attached to a Nikon Eclipse E800 compound microscope, and the resulting layers combined electronically using Auto-Montage and retouched as needed with Adobe ${ }^{\bullet}$ Photoshop $\mathrm{CS}^{\circ}$. Abbreviations used in the description are: $\mathrm{fl}_{\mathrm{x}}$ for funicle segment and $\mathrm{gt}_{\mathrm{x}}$ for gastral tergum.

\section{Alaptus group of genera}

The Alaptus-group of genera is distinguished by at least one apomorphy: in both sexes the anterior scutellum is separated from the posterior scutellum by a transverse suture that sometimes divides the scutellum into two completely separate sclerites (Figs 3, 8, 14). Huber and Lin (1999) and Lin et al. (2007) give additional diagnostic 
features. Taking into consideration the changes in classification proposed here, the Alaptus group now contains the following five genera: Alaptus, Dicopomorpha, Dicopus, Kikiki, and Mimalaptus.

Mimalaptus, illustrated here by M. victoria (Girault) (Figs 7-11) [on a slide with another mymarid species (Fig. 7)], resembles Dicopomorpha in having a 7-segmented (rarely 6-segmented) funicle in females (Figs 9, 11), but differs by the posterior scutellum being clearly divided medially by a longitudinal suture (Fig. 8) and the posterior margin of the fore wing having a distinct lobe behind the venation (Fig. 10). Mimalaptus is currently known only from the Australian region (Noyes and Valentine 1989, Lin et al. 2007) but I have seen specimens from the several countries in the Oriental region and Japan (Honshu) in the Palearctic region. Once the fauna is better known it may be better to treat Mimalaptus as a subgenus of Dicopomorpha because the structure of the posterior scutellum appears to be the only unequivocal difference that separates it from Dicopomorpha. I have also seen a fossil specimen from Baltic amber (together with a second, larger, piece of amber in box G 3.910 Hymenoptera \#BST03124, GeologicalPalaeontological Institute and Museum, Göttingen, Germany), indicating that it is or was much more widespread.

Dicopus is also a worldwide genus that resembles Dicopomorpha in having a 7-segmented funicle in females, but is distinguished from it and Mimalaptus by an extremely narrow fore wing and ventrally directed mandibles that do not cross over when closed. Several workers had independently recognized that Kubja is probably a synonym of Dicopus but this was never published. The wings (Fig. 19), mandibles (Figs 13, 15), female antenna (Fig. 16), male antenna (Fig. 17), and general body shape and structure of the mesosoma (Figs 12, 14, 15) of the type specimens ( 2 females and 1 male, Fig. 18) of Kubja longipes Subba Rao are the same as for species of Dicopus so the synonymy is formalized here as Kubja, syn. n. and the type species is transferred to Dicopus as Dicopus longipes (Subba Rao), comb. n.

While progress has been made in working out generic limits within the Alaptus group of genera, whose members are small even for Mymaridae, there is still uncertainty about generic limits. Further study of as many undescribed species, of Dicopomorpha and Alaptus in particular, is needed to determine if the current concepts and generic limits represent monophyletic lineages worthy of generic status.

\section{Key to Alaptus group of genera. Females.}

1 Tarsi 3- or 4-segmented; funicle 4- or 5-segmented; clava 2-segmented; mandible with 4 teeth.

Kikiki

- Tarsi 5-segmented; funicle at least 5-segmented; clava 1-segmented; mandible with 2 teeth.

2(1) Funicle 5-segmented or rarely with a minute additional segment; fore wing hind margin with a distinct, often recurved, notch behind venation and thereafter almost straight to apex 
- $\quad$ Funicle usually with 6 or 7 distinct segments (Figs 5, 9, 11, 16) but one Australian species of Dicopus with 5 segments; fore wing without a distinct notch on hind margin except one species of Dicopomorpha from New Zealand (Noyes and Valentine 1989) and hind margin either concave along much of length or only distally 3

3(2) Head in anterior view with mandibles projecting ventrally, not crossed when closed (Figs 13, 15); mandible with one long and one short tooth; fore wing extremely narrow (Figs 12, 19)

Dicopus

- $\quad$ Head in anterior view with mandibles crossed medially when closed (Figs 4, 9); mandible with two subequal teeth; fore wing wider (Figs 1, 6, 10) .......4

4(3) Posterior scutellum entire (Figs 3, 14)

Dicopomorpha

Posterior scutellum divided medially by a longitudinal suture (Fig. 8)

Mimalaptus

\section{Dicopomorpha Ogloblin}

Type species. D. macrocephala Ogloblin.

Diagnosis. Female antenna 7-segmented; mandibles with 2 subequal teeth and crossed when closed; fore wing progressively widening beyond venation, slightly curved apically, and with very few microtrichia on membrane, posterior scutellum (=frenum) entire.

List and distribution of described Dicopomorpha species [original genus in brackets].

D. echmepterygis Mockford, USA.

D. koreana S. Triapitsyn \& Berezovskiy, South Korea.

D. liaoningensis (Lou, Cao \& Lou) [Alaptus)], China.

D. macrocephala Ogloblin, Argentina.

D. maximus (Girault) [Eomymar], Australia.

D. pulchricornis (Ogloblin) [Chromodicopus], Argentina.

D. schleideni (Girault) [Litus], Australia.

D. stramineus (Ogloblin) [Dicopulus], Argentina.

D. victoria (Girault) [Dicopus], Australia.

D. zebra Huber, sp. n., equatorial West Africa.

\section{Dicopomorpha zebra Huber, sp. n.}

urn:Isid:zoobank.org:act:4888D434-FF76-4C16-B2E6-51DD85F4CC3D

Type material. Holotype female (BMNH) on slide (Fig. 2) labelled: 1. "Nigeria: Oyo, Ibadan, IITA compound, XI.1987, J.S. Noyes, Malaise trap". 2. "Dicopomorpha zebra Huber $q$ dorsal Holotype”. Paratypes: 11 females, 1 male (BMNH, CNC). GABON: 15-25 km N. Libreville, Forêt de la Mondah, 25 and 26.XI-3.XII.1987, J.S. Noyes (3 
females). IVORY COAST: Lamto, ca. $160 \mathrm{~km}$ NW Abijan, 502'W 6¹3’N, XI.1988, J.S. Noyes, XI.1988 (6 females) and 17.VII.1988 (1 female). NIGERIA: Oyo, Ibadan, IITA compound, XI.1987, J.S. Noyes (1 female, 1 male).

Diagnosis. The scape with two distinct, transverse, white bands and the pedicel white, contrasting with the brown flagellum (Figs 1, 5) distinguish this species from other (mostly undescribed) Dicopomorpha species.

Description. Female. Body length 285-585 ( $\mathrm{n}=8$, critical point dried specimens). Body (Fig. 1) shiny dark brown dorsally, with a faint but distinct mother-ofpearl (blue and green) sheen, especially on vertex and dorsum of mesosoma; head below eyes and between toruli yellowish; gaster lighter ventrally; coxae, trochanters, and parts of femora and tarsi lighter, almost white; scape with two transverse white bands; pedicel white.

Head (Figs 3, 4). Head width $1.4 \times$ length, and length about $1.0 \times$ height. Sculpture generally reticulate but shallow on face and gena, very faint on polished vertex (Fig. 3). Face in lateral view (Fig. 4) strongly angular and produced forward of anterior

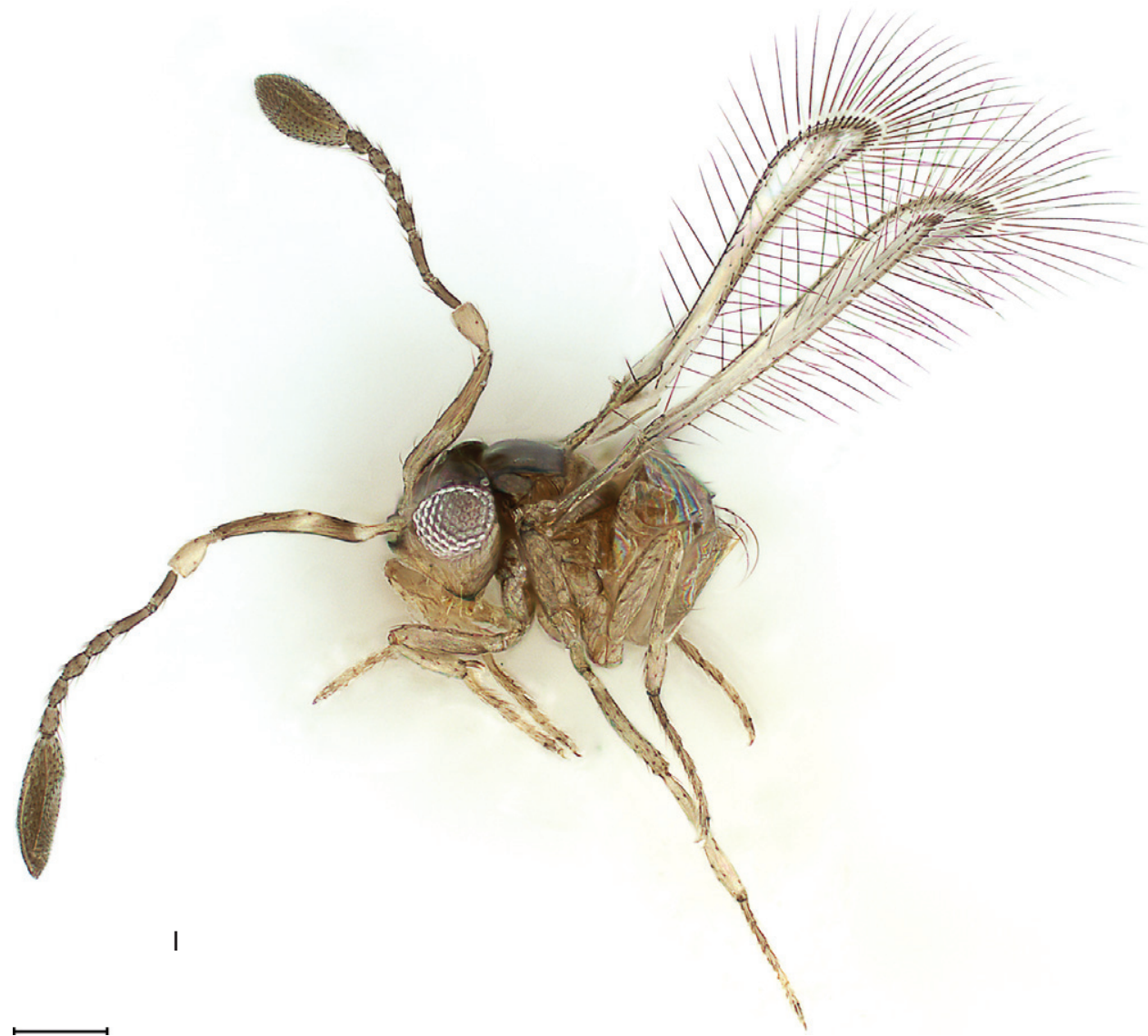

Figure I. Dicopomorpha zebra Huber, paratype female, habitus. Scale $=0.1 \mathrm{~mm}$. 
margin of eye, with a slightly undulating, sharp-edged junction separating a short, almost horizontal dorsal surface (bearing the toruli) from a strongly receding ventral surface. Vertex (Fig. 3) slightly curving to transverse trabecula anteriorly, its posterior margin concave and forming a sharp angle with occiput; median ocellus about its own diameter from posterior margin of vertex, lateral ocelli at posterolateral corners of vertex. Eye large, extending posteriorly to occiput in dorsal third, separated ventrally from occiput by increasingly widened gena; malar space slightly less than half eye height, with 2 setae. Face with 2 setae on dorsal surface between toruli, 2 setae on ventral

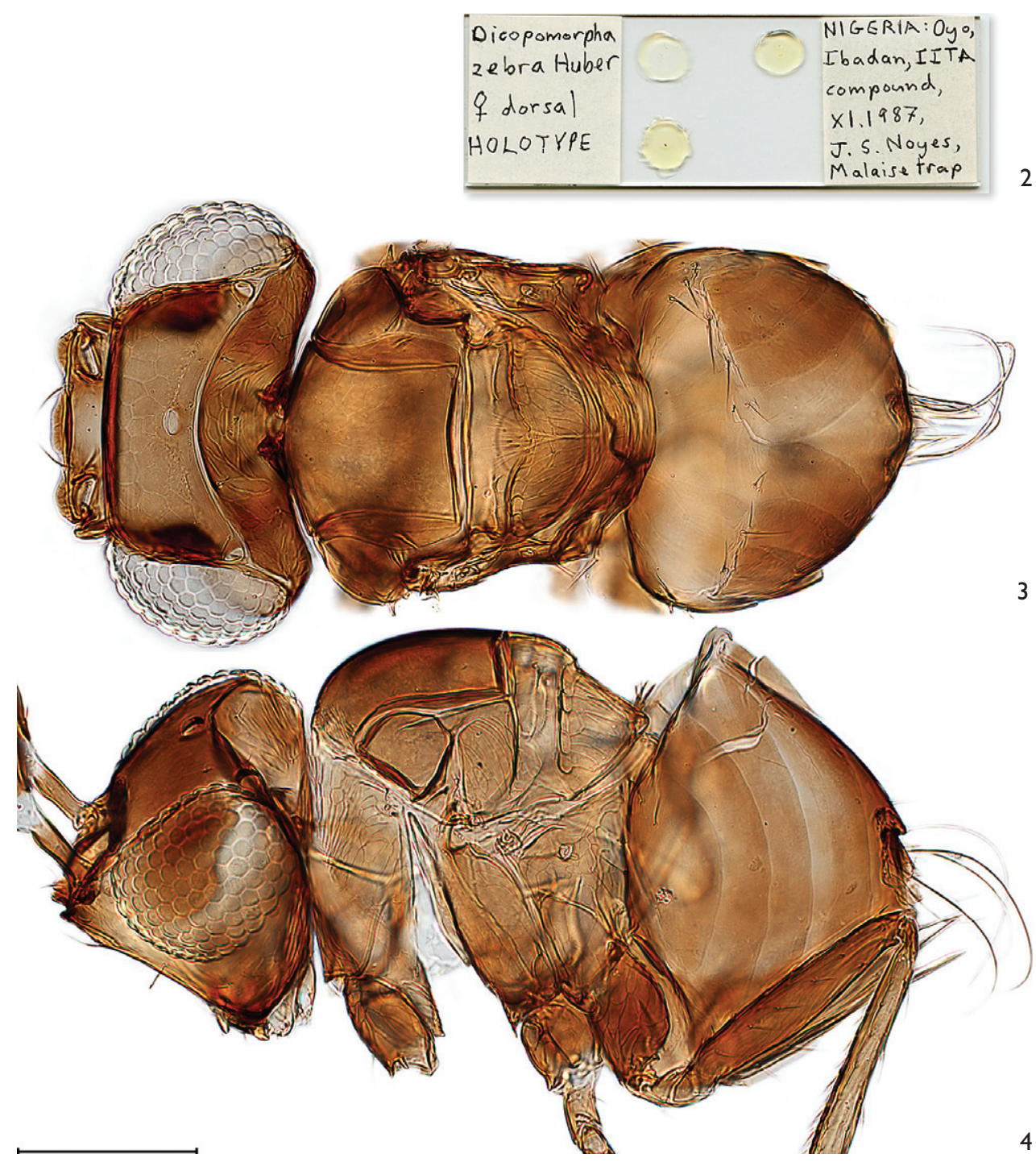

Figures 2-4. Dicopomorpha zebra $\mathbf{2}$ holotype slide, actual size $\mathbf{3}$ holotype female, body, dorsal $\mathbf{4}$ paratype female, body, lateral. Scale $=0.1 \mathrm{~mm}$. 
surface sublaterally just below junction with dorsal surface, and about 5 setae laterally along margin with eye and malar space; vertex with 2 minute setae behind median ocellus and 1 longer seta next to each lateral ocellus; occiput with 1 submedian dorsal setae just ventral to junction with vertex.

Antenna (Fig. 5). Scape usually with a prominent bulge ventrally in basal third beyond radicle, then narrowing to apex; radicle not separated from scape by a groove; pedicel almost $2 \mathrm{x}$ as long as wide; funicle 7 -segmented; $\mathrm{fl}_{2}$ quadrate, much shorter than remaining funicle segments, in particular $\mathrm{fl}_{1}$ and $\mathrm{fl}_{3}$; clava as long as $\mathrm{fl}_{4}-\mathrm{fl}_{7}$ and fairly wide. Measurements (length/width) of antennal segments (holotype): scape 206/47, pedicel 51/30, $\mathrm{fl}_{1}$ 50/11, $\mathrm{fl}_{2}$ 11/11, $\mathrm{fl}_{3}$ 57/14, $\mathrm{fl}_{4}$ 40/15, $\mathrm{fl}_{5}$ 43/17, $\mathrm{fl}_{6} 34 / 15, \mathrm{fl}_{7} 37 / 19$, clava 154/55. Clava with 3 longitudinal sensilla.

Mesosoma (Figs 1, 3, 4). Length slightly greater than width, with sculpture very faint, at most moderately visible on posterior scutellum (Fig. 3); most setae minute, barely visible. Pronotum extremely short and almost membranous medially, not visible

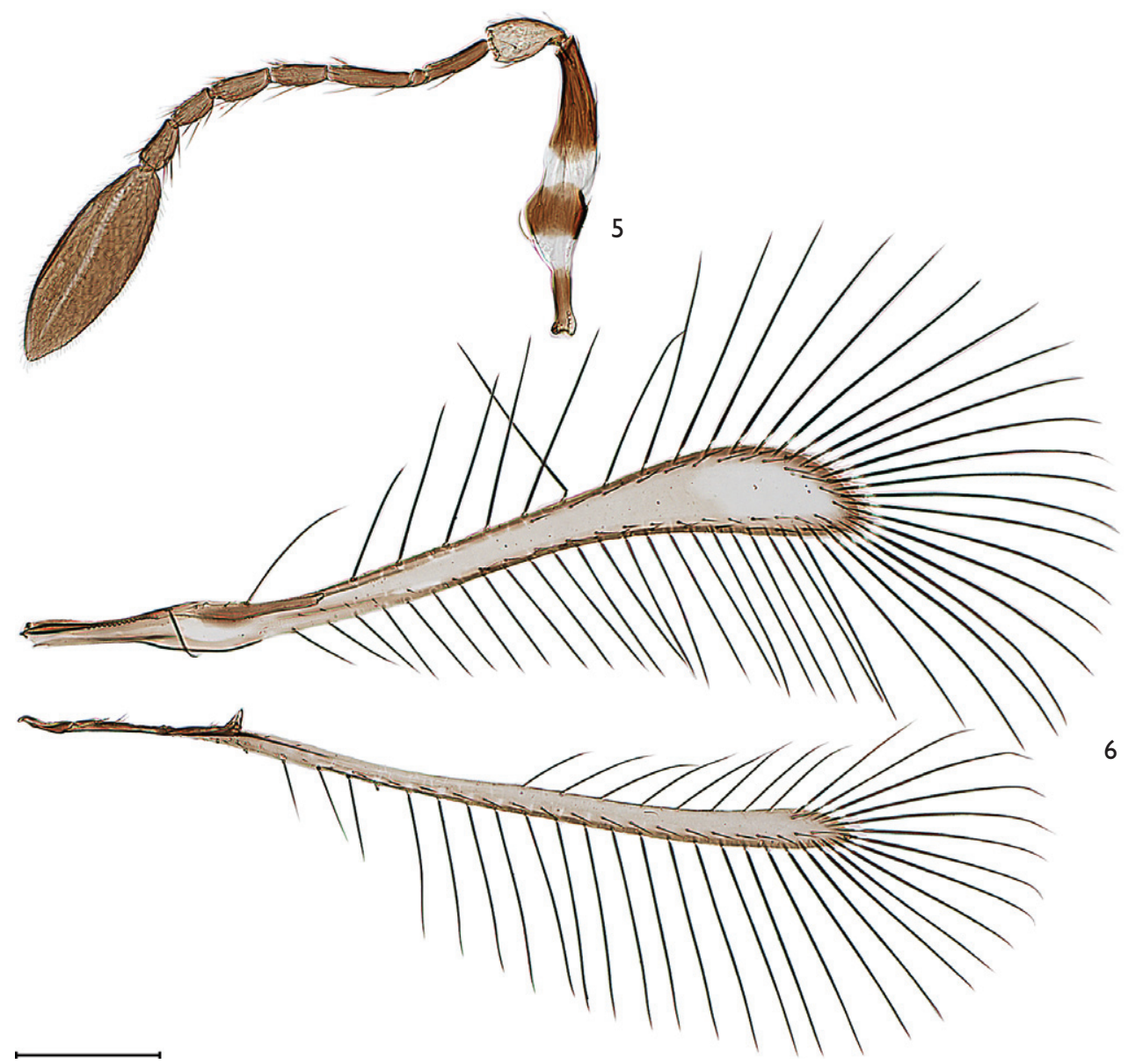

Figures 5-6. Dicopomorpha zebra, holotype 5 antenna 6 wings. Scale $=0.1 \mathrm{~mm}$. 

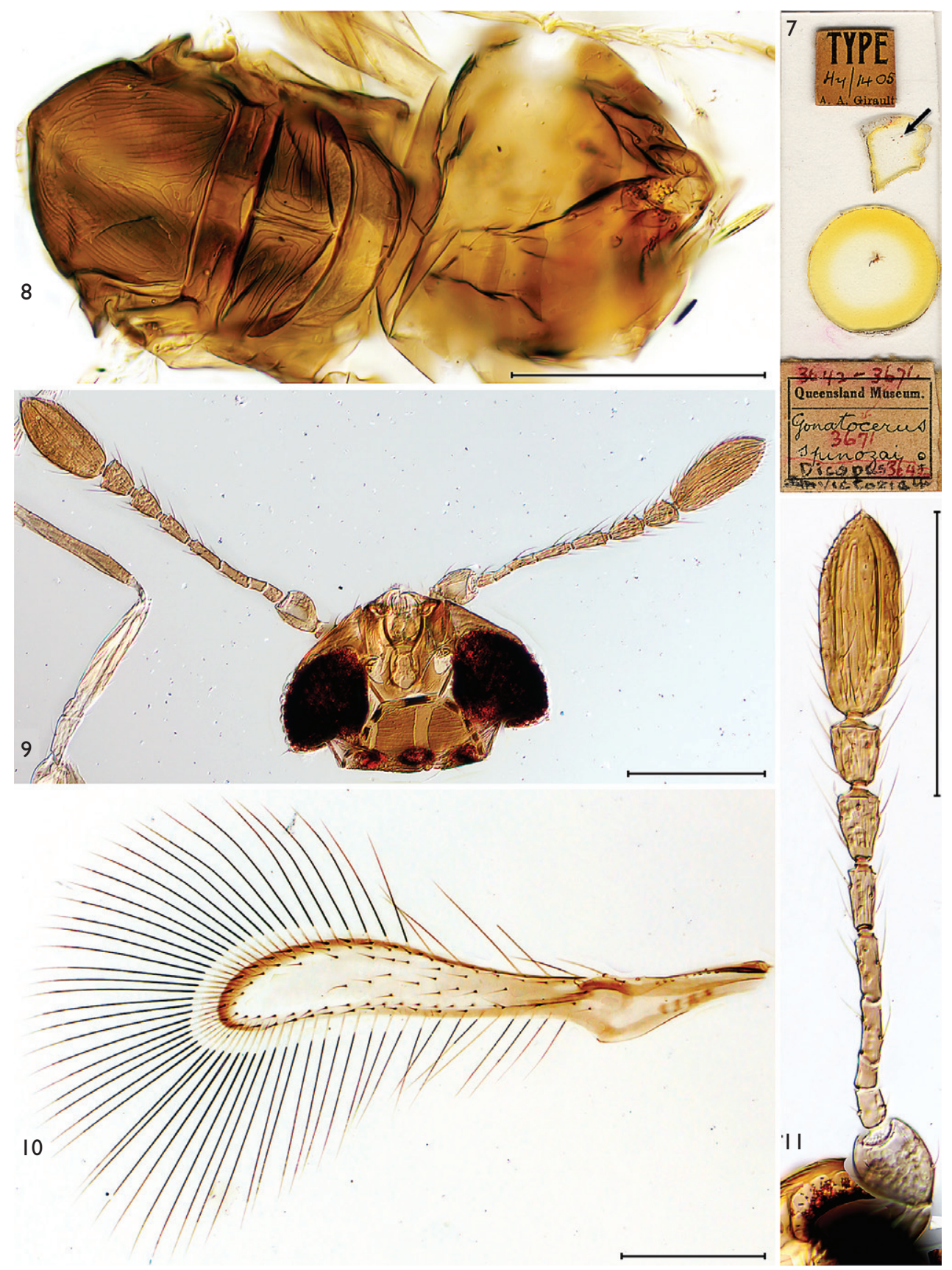

Figures 7-I I. Mimalaptus victoria (Girault) 7 holotype slide, actual size (together with holotype of Gonatocerus spinozai Girault; arrow indicates holotype of $M$. victoria) 8 holotype mesosoma + metasoma, dorsal 9 head, anterior + antennae (specimen on slide 2 in Dahms, 1986: 633) I 0 fore wing (same specimen as Fig. 9). I I holotype, antenna. Scale $=0.1 \mathrm{~mm}$. 

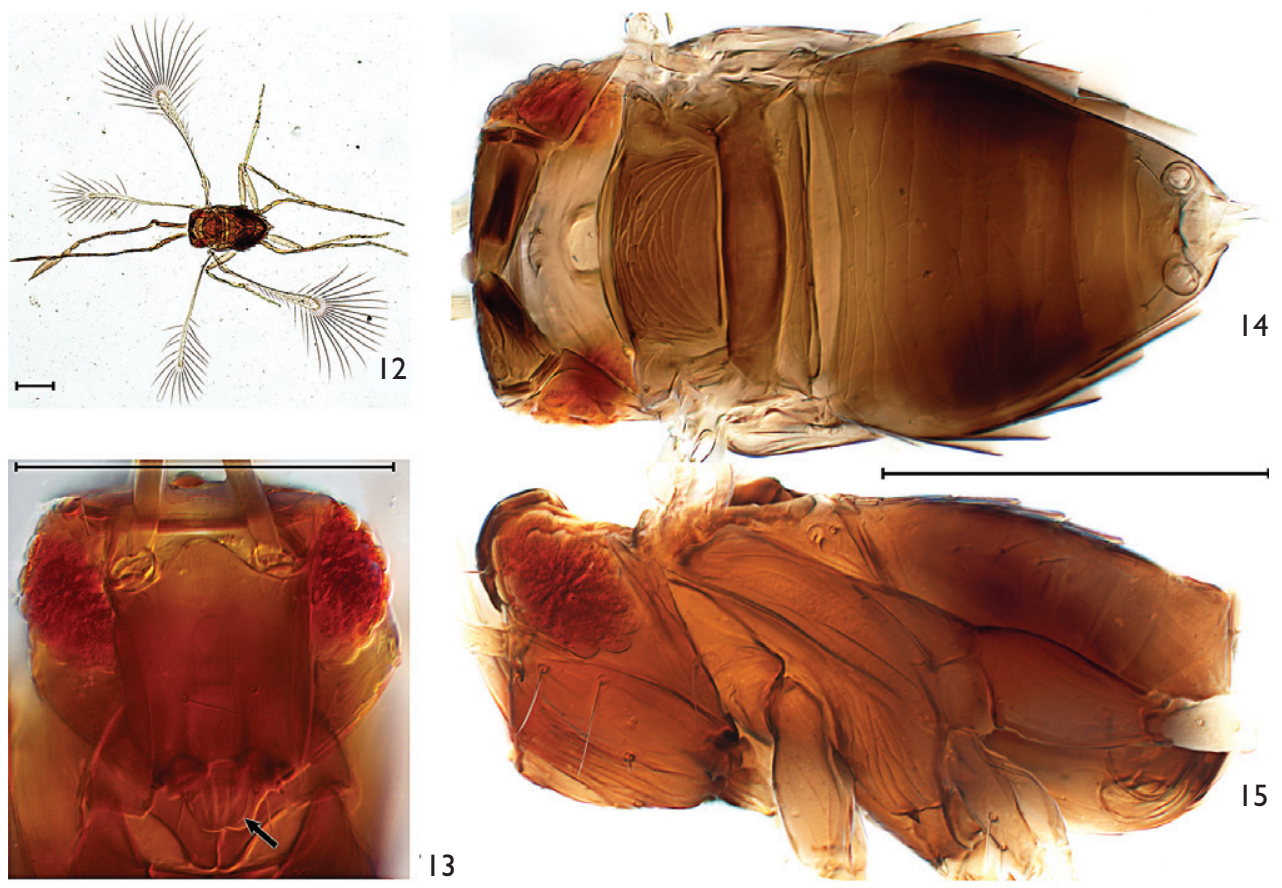

13

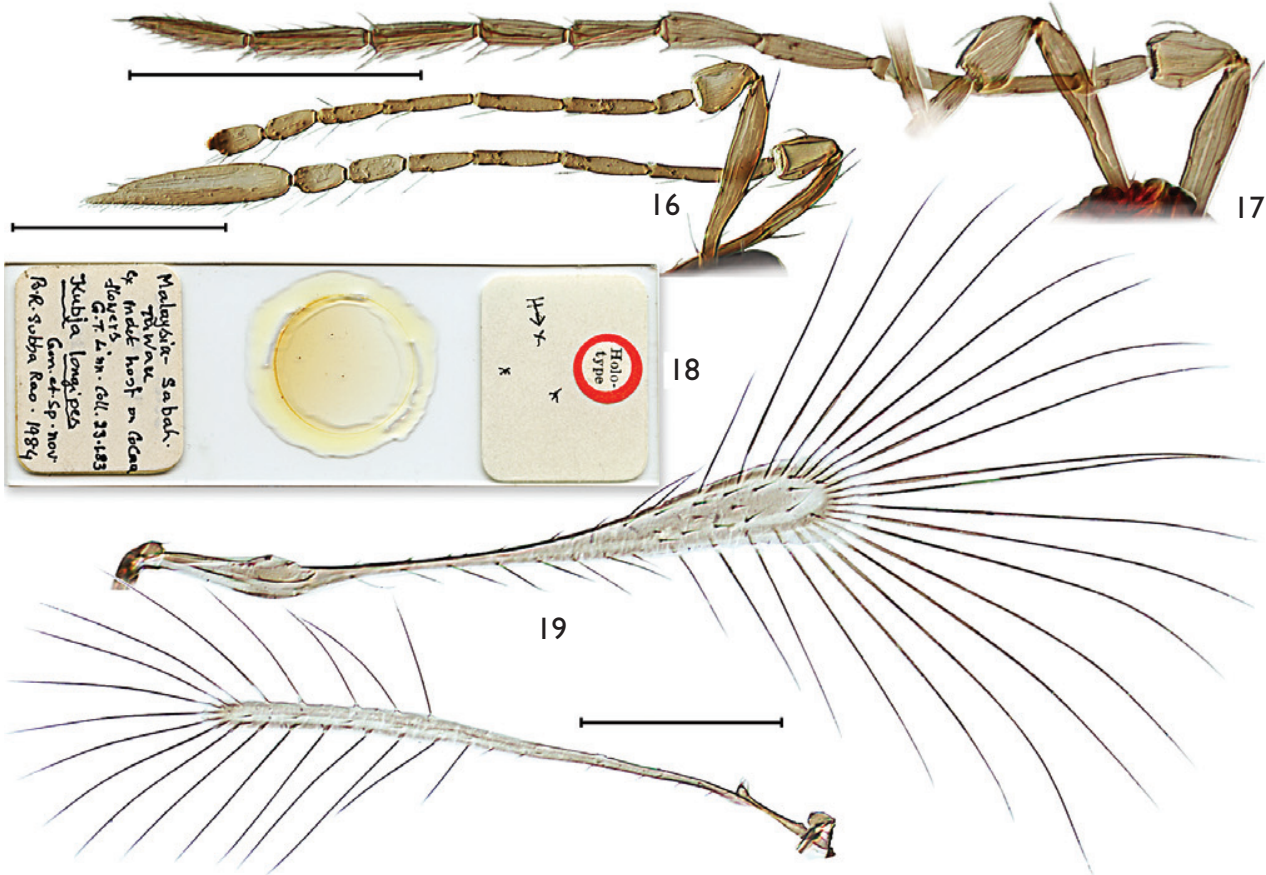

Figures 12-19. Dicopus longipes (Subba Rao), holotype (except as noted) $\mathbf{2}$ body, habitus $\mathbf{1} \mathbf{3}$ head, anterior (arrow indicates mandible) $\mathbf{1 4}$ body, dorsal $\mathbf{1 5}$ body, lateral (paratype, female) $\mathbf{1 6}$ antennae (paratype, female) $\mathbf{I} \mathbf{7}$ antenna (paratype, male) $\mathbf{1 8}$ holotype slide, actual size $\mathbf{1 9}$ wings (right forewing + left hindwing). Scale $=0.1 \mathrm{~mm}$. 
in dorsal view (Fig. 3); mesoscutum shiny (Fig. 3), with very faint sculpture, the lateral lobe prominent with 1 seta at lateral angle, and midlobe with 1 seta medially and 1 seta posteriorly near notaulus; axilla with 2 setae medially and posteriorly; anterior scutellum slightly longer than posterior scutellum medially, but shorter laterally, with the placoid sensilla widely separated and 1 seta just lateral to each sensillum; dorsellum short, about one-third length of posterior scutellum; propodeum short, slightly more than half length of posterior scutellum, the propodeal seta less than two spiracle diameters from spiracle.

Wings (Fig. 6). Fore wing with brown suffusion except behind base of marginal vein and an oval clear area beyond venation in apical quarter, disc without microtrichia except for the usual two rows along anterior and posterior margins. Hypochaeta near apex of submarginal vein; proximal macrochaeta absent, distal macrochaeta at apex of marginal vein at point where vein thins as stigmal vein. Hind wing with uniform brown suffusion, the membrane slightly and gradually widening towards rounded apex, with 1 row of microtrichia along hind margin. Fore wing length (holotype) 573, width 60, longest marginal setae 199, venation length 200. Hind wing length 569, width 19, longest marginal setae 154, venation length 150 .

Legs. Normal, with 5 tarsomeres.

Metasoma (Figs 3, 4). Slightly shorter than mesosoma, in dorsal view almost globular but with a distinctly sloping anterior face separated by a sharp ridge from posterodorsal face; the terga in dorsal view (Fig. 3) strongly oblique, arranged in a V-shaped pattern and except for $\mathrm{gt}_{7}$ appearing divided medially; with about 12 setae ( 2 on each of $\mathrm{gt}_{2}-\mathrm{gt}_{6}$, apparently) along the sharp ridge; cercal setae long (about 255) and curved; spiracle apparently absent. Ovipositor 345, equal in length to metatibia.

Male. Body length 426 ( $n=1$, critical point dried). Body brown except gaster light brown and base of scape white. Antennal length 1064, 2.5 times length of entire body, apparently with 9 flagellar segments; each flagellomere about $5 \times$ as long as wide; $\mathrm{fl}_{4}$ length 100 .

Variation. Three of the paratypes from Lamto have the scape narrower basally and the white bands less distinct (Fig. 1) than in the other types.

Derivation of species name. Named after the mammal; a noun in apposition referring to the distinctively striped scape of the female antenna.

Discussion. Initially, I considered that D. zebra represented a new genus related to Dicopomorpha because the funicle is 7-segmented in females and the 2-toothed mandibles cross over when closed, but it exhibits several features that appeared to be very different from other species classified in the genus: 1) the body, especially the vertex and mesosoma, with a faint but distinct mother-of-pearl sheen and scarcely any visible sculpture or setae, 2) the head in lateral view strongly angular, the face distinctly projecting forward in front of eyes, 3) the fore wing distinctly curved, with the hind margin concave distally and with almost no microtrichia on disc except along margins, and 4) the short, almost globular metasoma with strongly oblique, V-shaped terga. However, study of a diversity of mostly undescribed species from five continents failed to yield a single feature could be used to distinguish 
unequivocally my proposed genus. One or more of the features listed above occur in one or more other species that clearly belong to Dicopomorpha. Indeed, it was not even worth segregating $D$. zebra into a new subgenus, though it might be worth treating it as a representative of a species group defined by the relatively wide and apically curved fore wing. The generic synonymy in the species list above already suggested not only that Dicopomoropha is morphologically diverse but also showed that it was easily confused with related genera. To propose yet more genera would begin (again) a trend to oversplit Dicopomorpha, which could result in the unfortunate situation of more and more finely divided genera whose limits could not be determined with certainty.

\section{Acknowledgments}

I thank J. Noyes (BMNH) for loaning the types of Kubja longipes and specimens of Dicopomorpha for study. J. Read is gratefully acknowledged for preparing the images and compiling the plates of illustrations.

\section{References}

Dahms, EC (1986) A checklist of the types of Australian Hymenoptera described by Alexandre Arsene Girault: IV. Chalcidoidea species N-Z with advisory notes. Memoirs of the Queensland Museum 22: 319-739.

Huber, JT (1997) Chapter 14. Mymaridae. In: Gibson, GAP, Huber, JT and Woolley, JB (Eds) Annotated keys to the genera of Nearctic Chalcidoidea (Hymenoptera). NRC Research Press, Ottawa, 499-530

Huber JT and Lin NQ (1999) World review of the Camptoptera group of genera (Hymenoptera: Mymaridae). Proceedings of the Entomological Society of Ontario 130: 21-65.

Lin NQ, Huber JT, La Salle J (2007) The Australian genera of Mymaridae Hymenoptera: Chalcidoidea). Zootaxa 1596. 1-111

Mockford EL (1997) A new species of Dicopomorpha (Hymenoptera: Mymaridae) with diminutive, apterous males. Annals of the Entomological Society of America 90: 115-120.

Noyes JS and Valentine EW (1989) Mymaridae (Insecta: Hymenoptera) - introduction, and review of genera. Fauna of New Zealand 17.95 pp.

Ogloblin A (1955) Los nuevos representantes de la fam. Mymaridae (Hym.) de la República Argentina. Bollettino del Laboratorio di Zoologia Generale e Agraria "Filippo Silvestri", Portici 33: 377-397.

Triapitsyn SV and Berezovskiy VV (2003) Review of the Mymaridae (Hymenmoptera, Chalcidoidea) of Primorskii krai: genera Arescon Walker and Dicopomorpha Ogloblin. Far Eastern Entomologist 124: 1-15. 
Triapitsyn SV, Berezovsky VV (2004) Review of the genus Litus Haliday, 1833 in the Holarctic and Oriental regions, with notes on the Palaearctic species of Arescon Walker, 1846 (Hymenoptera: Mymaridae). Far Eastern Entomologist 141: 1-24.

Triapitsyn SV, Huber JT (2000) 51. Fam. Mymaridae - mymarids. In: Lehr, PA (Ed) Key to the insects of Russian Far East. Vol. IV. Neuropteroidea, Mecoptera, Hymenoptera. Pt. 4. Dal'nauka, Vladivostok. 603-614, 651. In Russian.

Yoshimoto CM (1990) A review of the genera of New World Mymaridae (Hymenoptera: Chalcidoidea). Flora \& Fauna Handbook no. 7. Sandhill Crane Press, Gainesville, Florida. 166 pp. 